\title{
Utilização da raiz de mandioca desidratada, em substituição ao milho, na suplementação de vacas holandesas em pastejo sobre o consumo voluntário, digestibilidade aparente e metabolismo energético
}

\section{Use of dried cassava root to replace corn in supplementation of Holstein cows grazing and consuming spontaneously, apparent digestibility and energy metabolism}

\author{
Ádler Carvalho da Silva ${ }^{1 *}$; Yann dos Santos Luz'; Mauro Pereira de Figueiredo ${ }^{3}$; \\ Paulo Bonomo ${ }^{3}$; Mara Lúcia Albuquerque Pereira ${ }^{3}$; \\ Cleia Gomes Vieira e Silva Medeiros ${ }^{4}$
}

\section{Resumo}

O experimento foi realizado para avaliar o efeito da substituição do milho moído por raiz integral de mandioca moída e desidratada nos níveis $0 \%, 25 \%, 50 \%, 75 \%$ e $100 \%$ nos suplementos experimentais para vacas lactantes mantidas em pastagens tropicais irrigadas e adubadas. Foram utilizadas 10 vacas da raça Holandesa, divididas em dois quadrados latinos 5x5, com média inicial de 150 dias de lactação, produção leiteira inicial de lactação de $22 \mathrm{~kg} /$ dia e peso corporal inicial médio de $603 \mathrm{~kg}$, mantidos em pastagem formada por capim elefante (Pennisetum purpureum, SCHUM) cultivar pioneiro, consorciado com capim Tifton 85 (Cynodon nlemfuensis), irrigadas e adubadas com $600 \mathrm{~kg}$ de nitrogênio por hectare/ ano. Não foram encontrados efeitos significativos de substituição do milho moído por raiz integral de mandioca moída e seca no concentrado $(\mathrm{P}>0,05)$, sobre o consumo voluntário da dieta total, com média estimada de 20,61 kg/MS/animal/dia, digestibilidade aparente da MS com média estimada de 59,60\% e balanço de energia, com média estimada de $+6,36 \mathrm{Mcal} \mathrm{dia}^{-1}$. Os resultados deste estudo demonstram que a raiz de mandioca pode ser utilizada como fonte energética de alto valor nutricional, semelhante ao do milho, na suplementação de vacas lactantes mantidas em pastagens tropicais.

Palavras-chave: Carboidratos, forrageiras, ingestão, nutrição

\footnotetext{
Abstract

The development of this experiment intended to evaluate the effect of replacing ground corn for dried and ground cassava roots with the levels of $0 \%, 25 \%, 50 \%, 75 \%$ and $100 \%$ in the experimental supplements for lactating cows kept on tropical irrigated and fertilized pastures. Ten Holstein cows were divided into two $5 \times 5$ Latin squares, with an initial lactation average of 150 days, $22 \mathrm{~kg} /$ day of average milk production of lactation and approximate initial average body eight of $603 \mathrm{~kg}$. The animals were kept in pasture constituted by elephant grass (Pennisetum purpureum, SCHUM) cv Pioneer, associated

${ }^{1}$ Discente de Doutorado em Produção de Ruminantes, Universidade Estadual do Sudoeste da Bahia, UESB, Itapetinga, BA. E-mail: adlerzootecnia@yahoo.com.br

2 Discente de Doutorado, UESB, Itapetinga, BA. E-mail: yann agronomia@yahoo.com.br

${ }^{3}$ Profs., Pesquisadores, UESB, Itapetinga, BA. E-mail: mfigue2@yahoo.com.br; bonomopaulo@gmail.com; marauesb@yahoo. com.br

${ }^{4}$ Pesquisadora, UESB, Itapetinga, BA. E-mail: cgvs@hotmail.com

* Autor para correspondência
} 
with Tifton 85 grass (Cynodon nlemfuensis), irrigated and fertilized with $600 \mathrm{~kg}$ of nitrogen per hectare/ year. No significant effects on the substitution of ground corn for dried and ground cassava roots in the concentrate $(\mathrm{P}>0.05)$ over the spontaneous consumption of the total diet, with estimated average of $20.61 \mathrm{~kg} / \mathrm{DM} / \mathrm{animal} /$ day, apparent digestibility of DM with estimated average of $59.60 \%$ and energy balance with estimated average of $+6.36 \mathrm{Mcal} \mathrm{day}^{-1}$. The results of this study demonstrate that the cassava root can be used as an energy source of high nutritional value for supplementation of lactating cows grazing on tropical pastures, similar to corn results.

Key words: Carbohydrates, grass, consumption, nutrition

\section{Introdução}

A intensificação nos sistemas de manejo de pastagens tropicais por meio de fertilização nitrogenada e irrigação proporciona redução dos efeitos de estacionalidade na produção de forragem, tornando mais homogênea a oferta de volumoso durante o ano, contribuindo no sistema de produção de leite em pastagem.

Devido à capacidade limitada de oferta de nutrientes através das forrageiras, faz-se necessário a utilização de suplementação concentrada, com nutrientes balanceados de modo a elevar a produtividade leiteira e potencializar a utilização dos nutrientes dietéticos pelos microrganismos ruminais.

A função primordial dos carboidratos para os ruminantes está no provimento de energia para os microrganismos ruminais, bem como para o animal hospedeiro (RAMALHO et al., 2006).

O amido é a principal fonte de energia dos grãos e raízes, utilizadas na alimentação de ruminantes e, devido a sua constituição molecular, apresenta disponibilidade energética superior à dos carboidratos estruturais presentes nas dietas dos bovinos.

A avaliação de fontes energéticas regionais, que tenham condições de substituir total ou parcialmente os alimentos convencionalmente utilizados, é justificada pela necessidade de se potencializar a utilização destes ingredientes.

$\mathrm{O}$ amido da mandioca apresenta maior degradabilidade efetiva em relação ao do milho, devido à inexistência de pericarpo, endosperma córneo e periférico, e matriz proteica (RANGEL et al., 2008).

O objetivo foi avaliar a substituição do milho moído pela raiz de mandioca integral triturada e desidratada no concentrado de vacas lactantes, sobre o consumo voluntário, digestibilidade aparente e balanço energético.

\section{Material e Métodos}

O ensaio foi realizado em uma propriedade comercial de produção de leite denominada Sítio Beija-Flor, localizada nas Terras do Remanso, no município de Vitoria da Conquista, Estado da Bahia. Esta propriedade rural situa-se geograficamente às coordenadas $14^{\circ} 51^{\prime} 38^{\prime \prime} \mathrm{S}$ e $40^{\circ} 52^{\prime} 51^{\prime \prime} \mathrm{O}$, com altitude de 923 metros.

O experimento foi realizado no período de março a maio de 2012, utilizando-se 10 vacas da raça Holandesa, média inicial de 150 dias de lactação, produção leiteira média ao início do ensaio de $22 \mathrm{~kg}$ e peso corporal inicial médio de $603 \mathrm{~kg}$. Estas foram submetidas a cinco tratamentos, em delineamento experimental, quadrado latino 5 x 5 (cinco animais, cinco períodos e cinco tratamentos), sendo usados dois quadrados simultaneamente. As vacas foram mantidas em pastagem predominante de capim elefante (Pennisetum purpureum, SCHUM) C.V. Pioneiro consorciado com capim Tifton 85 (Cynodon nlemfuensis), irrigada e adubada com 600 $\mathrm{kg}$ de nitrogênio por hectare/ano.

A duração do ensaio foi de 75 dias, com 10 dias de adaptação para cada período, seguidos de 5 dias de coleta de dados. Os animais foram suplementados 
com concentrados experimentais, contendo diferentes proporções de milho moído e raiz de mandioca integral moída e desidratada, calculados para serem isoenergéticos e isonitrogenados. As dietas foram formuladas para atender às exigências de mantença e produção de 25 litros de leite com $3,8 \%$ de gordura (NRC, 2001).

$\mathrm{Na}$ avaliação de consumo, digestibilidade e balanço de energia, foi utilizado apenas um quadrado latino composto por cinco animais.

No fornecimento de todos os concentrados experimentais no cocho, foram acrescentadas aparas de casca da raiz de mandioca fresca como forma de facilitar a ingestão do concentrado farelado. O total do fornecido no cocho continha a proporção média de $70 \%$ de concentrado e $30 \%$ de aparas ( $\% \mathrm{MS})$.

Os suplementos concentrados foram fornecidos duas vezes ao dia, pela manhã e tarde, após a ordenha.
Os cochos eram de cimento, individualizados, cobertos por telhado de fibrocimento.

As vacas foram mantidas em uma área de 2,05 hectares em sistema de pastejo rotacionado, composta pelas gramíneas Penissetum purpureum Schum C.V. Pioneiro (gramínea predominante), consorciado com Cynodon nlenfluensis. Aárea estava dividida em 41 piquetes, com aproximadamente $494 \mathrm{~m}^{2}$, com oferta média de forragem de $70 \mathrm{~kg}$ de matéria natural/animal/dia. Os animais iniciavam o consumo das forrageiras do piquete em uso, após a ordenha da tarde, aproximadamente às 18h30, e deixavam o piquete às $17 \mathrm{~h}$ do dia seguinte.

Os concentrados experimentais utilizados no experimento foram compostos por milho, que foi substituído por mandioca em diferentes níveis (base da matéria seca; $0 \%, 25 \%, 50 \%, 75 \%, 100 \%$ ) (Tabela 1).

Tabela 1. Composição percentual dos concentrados avaliados.

\begin{tabular}{lccccc}
\hline \multicolumn{1}{c}{ Ingredientes } & \multicolumn{5}{c}{ Níveis de substituição $^{2}$} \\
\cline { 2 - 6 } & 0 & 25 & 50 & 75 & 100 \\
\hline Milho moído $^{1}$ & 72 & 54 & 36 & 18 & 0 \\
Raiz de Mandioca integral triturada e seca $^{1}(()(((\%)$ & 0 & 18 & 36 & 54 & 72 \\
Farelo de Soja $^{1}$ & 3,53 & 8,93 & 14,33 & 19,73 & 25,13 \\
Farelo de Algodão $^{1}$ & 21,97 & 16,57 & 11,17 & 5,77 & 0,37 \\
Ureia $^{1}$ & 2,5 & 2,5 & 2,5 & 2,5 & 2,5 \\
\hline
\end{tabular}

${ }^{1}(\%)$ : Percentual de inclusão do ingrediente na dieta concentrada; ${ }^{2}(\%)$ : Níveis de substituição do milho moído por raiz de mandioca integral triturada e seca na dieta concentrada, com base na matéria seca.

Fonte: Elaboração dos autores.

Os animais receberam no cocho, $300 \mathrm{~g}$ de mistura mineral e $250 \mathrm{~g}$ de bicarbonato de sódio, que foram fornecidos nos períodos da manhã e da tarde, misturados ao concentrado, e aparas de casca de raiz de mandioca fresca. Os níveis de garantia do suplemento mineral utilizado foram: Cálcio (mín) - 190,00 g kg-1e (máx) - 220,00 g $\mathrm{kg}^{-1}$; Fósforo (mín) - 60,00 $\mathrm{g} \mathrm{kg}^{-1}$; Enxofre (mín) - 20,00 $\mathrm{g} \mathrm{kg}^{-1}$; Magnésio (mín) - 20,00 mg kg-1; Potássio (mín) - 35,00 g kg-1; Sódio (mím) - 70,00 $\mathrm{g} \mathrm{kg}^{-1}$; Cobalto (mín) - 15,00 mg kg-1; Cobre (mín) - 700,00 mg kg-1; Cromo (mín) - 10,00 mg kg-1; Ferro (mín) - 700,00 mg kg-1; Iodo (mín) - 40,00 $\mathrm{mg} \mathrm{kg}{ }^{-1}$; Monesina sódica - 1.000,00 mg kg-1; Manganês (mín) - 1.600,00 mg kg-1; Selênio (mín) - 19,00 mg kg-1; Zinco (mín) - 2.500,00 mg kg-1; Vitamina A (mín) - 200.000,00 UI kg-1; Vitamina D3 (mín) - 50.000,00 UI kg-1; Vitamina E (mín) $1.500,00 \mathrm{UI} \mathrm{kg}^{-1}$; Flúor (máx) - 600, $\mathrm{mg} \mathrm{kg}^{-1}$. 
A composição químico-bromatológica em purpureum Schum) C.V. Pioneiro consorciado com percentual da matéria seca dos concentrados, capim Tifton 85 (Cynodon nlemfuensis). A pastagem aparas de casca de raiz de mandioca (ACRM) e foi amostrada usando a técnica de pastejo simulado, do volumoso composto pelos capins (Pennisetum em cada período de coleta de dados (Tabela 2).

Tabela 2. Composição químico-bromatológica dos concentrados experimentais, das aparas de casca de raiz de mandioca (ACRM) e da pastagem.

\begin{tabular}{|c|c|c|c|c|c|c|c|c|c|c|c|}
\hline \multirow{2}{*}{ Nutrientes $^{1}$} & \multicolumn{5}{|c|}{ Níveis de Substituição (\% MS) } & \multirow{2}{*}{ ACRM } & \multicolumn{5}{|c|}{ Pastagem (Períodos) } \\
\hline & 0 & 25 & 50 & 75 & 100 & & 1 & 2 & 3 & 4 & 5 \\
\hline MS & 80,83 & 80,31 & 79,68 & 79,42 & 79,84 & 35,09 & 18,11 & 19,04 & 19,06 & 18,61 & 20,49 \\
\hline MO & 97,67 & 97,60 & 97,76 & 97,57 & 97,45 & 93,10 & 88,89 & 89,44 & 88,36 & 88,61 & 88,44 \\
\hline PB & 24,31 & 21,40 & 21,14 & 21,24 & 21,94 & 7,49 & 15,10 & 15,91 & 12,78 & 15,21 & 16,16 \\
\hline EE & 6,45 & 4,80 & 3,13 & 1,92 & 1,24 & 1,85 & 3,44 & 4,03 & 3,79 & 4,28 & 4,47 \\
\hline FDNcp & 19,84 & 18,14 & 13,34 & 11,74 & 9,96 & 12,72 & 54,69 & 55,47 & 53,06 & 53,06 & 52,42 \\
\hline FDA & 12,23 & 9,38 & 9,07 & 8,97 & 8,94 & 17,20 & 34,64 & 36,91 & 38,69 & 32,97 & 35,75 \\
\hline FDNi & 4,07 & 4,38 & 4,40 & 4,04 & 4,98 & 13,98 & 10,62 & 11,74 & 9,19 & 10,50 & 9,69 \\
\hline CINZAS & 2,33 & 2,4 & 2,24 & 2,43 & 2,55 & 6,90 & 11,11 & 10,56 & 11,64 & 11,39 & 11,56 \\
\hline LIGNINA & 2,80 & 3,15 & 4,89 & 4,73 & 5,62 & 8,66 & 4,34 & 4,35 & 6,54 & 6,55 & 8,74 \\
\hline CHOT & 65,38 & 64,94 & 68,74 & 73,56 & 74,27 & 83,76 & 70,35 & 69,50 & 71,79 & 69,13 & 67,81 \\
\hline $\mathrm{CNF}$ & 49,03 & 55,20 & 60,95 & 62,20 & 63,18 & 74,93 & 15,66 & 14,03 & 18,73 & 16,06 & 15,39 \\
\hline $\mathrm{NDT}^{2}$ & 83,81 & 83,18 & 83,00 & 83,52 & 83,02 & 78,20 & 61,50 & 40,53 & 44,01 & 48,77 & 54,65 \\
\hline PDR & 72,63 & 73,94 & 73,70 & 76,43 & 73,76 & 72,48 & 76,34 & 74,87 & 73,69 & 75,88 & 72,60 \\
\hline PNDR & 27,37 & 26,06 & 26,30 & 23,57 & 26,24 & 27,52 & 23,66 & 25,13 & 26,31 & 24,12 & 27,40 \\
\hline \multicolumn{12}{|c|}{ Fracionamento de Proteínas ${ }^{3}$} \\
\hline A & 44,91 & 47,36 & 47,01 & 52,55 & 47,06 & 49,60 & 44,02 & 40,39 & 38,29 & 42,77 & 35,38 \\
\hline $\mathrm{B}_{1}+\mathrm{B}_{2}$ & 54,82 & 52,41 & 52,73 & 47,16 & 52,58 & 37,39 & 55,26 & 58,98 & 61,14 & 56,60 & 63,79 \\
\hline $\mathrm{B}_{3}$ & 0,01 & 0,09 & 0,04 & 0,04 & 0,12 & 4,34 & 0,48 & 0,51 & 0,15 & 0,51 & 0,47 \\
\hline $\mathrm{C}$ & 0,26 & 0,14 & 0,22 & 0,25 & 0,23 & 8,66 & 0,24 & 0,12 & 0,42 & 0,12 & 0,37 \\
\hline \multicolumn{12}{|c|}{ Fracionamento de Carboidratos ${ }^{4}$} \\
\hline A & 48,80 & 43,34 & 38,10 & 37,31 & 36,46 & 24,21 & 12,82 & 11,04 & 12,38 & 10,21 & 6,67 \\
\hline $\mathrm{B}_{1}$ & 46,94 & 53,40 & 59,97 & 61,38 & 62,55 & 72,37 & 2,38 & 1,80 & 2,85 & 1,95 & 1,21 \\
\hline $\mathrm{B}_{2}$ & 0,16 & 0,09 & 0,16 & 0,10 & 0,09 & 0,27 & 76,71 & 78,83 & 73,16 & 75,77 & 75,91 \\
\hline $\mathrm{C}$ & 4,10 & 3,17 & 2,28 & 1,21 & 0,90 & 3,16 & 8,09 & 8,33 & 11,60 & 12,07 & 16,21 \\
\hline
\end{tabular}

MS - matéria seca; MO - matéria orgânica; PB - proteína bruta; EE - extrato etéreo; FDNcp - fibra em detergente neutro corrigido para cinzas e proteína; FDA - fibra em detergente ácido; FDNi - fibra em detergente neutro indigestível; CHOT - carboidratos totais; CNF - carboidratos não fibrosos; NDT - nutrientes digestíveis totais. ${ }^{1} \%$; ${ }^{2} \mathrm{O}$ calculo do NDT foi realizado segundo o NRC (2001) por meio da fórmula: NDT (\%) $=\mathrm{CNF}_{\mathrm{d}}+\mathrm{PB}_{\mathrm{d}}+\left(\mathrm{EE}_{\mathrm{d}} * 2,25\right)+\mathrm{FDN}_{\mathrm{d}}-7$. PDR - Proteína Degradável no Rúmen; PNDR Proteína Não Degradável no Rúmen. ${ }^{3}$ Fracionamento de Proteínas: $\mathrm{A}$ - nitrogênio não protéico; $\mathrm{B}_{1}+\mathrm{B}_{2}-$ fração proteica insolúvel com taxa de degradação rápida e intermediária no rúmen; $\mathrm{B}_{3}$ - fração proteica insolúvel com taxa de degradação lenta no rúmen; $\mathrm{C}$ - fração protéica insolúvel no rúmen e indigestível no trato gastrintestinal. ${ }^{4}$ Fracionamento de Carboidratos: A- fração rapidamente degradável no rúmen, carboidratos solúveis; $\mathrm{B}_{1}$ - fração composta de amido e pectina, com taxa de degradação ruminal superior à taxa de passagem; $\mathrm{B}_{2}$ - fração composta por carboidratos fibrosos da parede celular, de lenta degradação ruminal; C - fração composta por parede celular indisponível.

Fonte: Elaboração dos autores. 
As sobras do alimento fornecido no cocho (concentrado experimental e aparas de casca de raiz de mandioca) foram mensuradas diariamente, após o consumo voluntário do fornecido. As sobras foram pesadas em balança digital e os pesos foram anotados para posterior avaliação da quantidade consumida no cocho. No período de coleta de dados, foi amostrada uma alíquota das sobras que foram armazenadas em sacos plásticos identificados, para posterior análise bromatológica.

Por meio da simulação de pastejo, foi realizada a amostragem das gramíneas, para posterior realização de análise bromatológica. A amostragem foi realizada do $10^{\circ}$ ao $15^{\circ}$ dia de cada período experimental. Foram amostrados 300 gramas de volumoso, colhidos manualmente, simulando o hábito de pastejo, em altura acima de $40 \mathrm{~cm}$ do solo, que é a altura de resíduo utilizada no manejo de saída dos animais nos piquetes. Para alocação do ponto de coleta da amostra, utilizou-se um quadrado de $1 \mathrm{~m}^{2}$ de área, que foi lançado aleatoriamente no piquete (DERESZ, 2001). As amostras colhidas diariamente foram embaladas em sacos plásticos identificados e resfriados, e ao final do período de coleta, estas amostras foram homogeneizadas e, depois, retirada uma alíquota que, novamente, foi embalada em saco plástico, identificado e conservado a $-10^{\circ} \mathrm{C}$, para posterior análise bromatológica.

A produção fecal individual foi estimada utilizando-se o indicador externo LIPE® $500 \mathrm{mg}$. O LIPE foi fornecido durante sete dias, sendo os três dias iniciais para estabilização da excreção do marcador pelas fezes e os quatro dias restantes para amostragem de fezes para análise. O indicador (cápsula de $500 \mathrm{mg} / \mathrm{vaca}$ ) foi administrado via oral, diariamente, após a ordenha da manhã.

O processo de coleta de fezes ocorreu entre o $10^{\circ}$ e $13^{\circ}$ dias experimentais de cada período. A amostragem de fezes foi realizada no período da manhã, colhendo-se as fezes por defecação espontânea ou diretamente na ampola retal. As amostras individuais coletadas foram armazenadas em sacos plásticos, identificadas e conservadas a $-10^{\circ} \mathrm{C}$ para posterior preparo e determinação da concentração do marcador nas fezes e estimativa da produção fecal individual.

As amostras de fezes foram descongeladas e desidratadas em estufa de ventilação forçada, a $65^{\circ} \mathrm{C}$. Após desidratadas, foram moídas em moinho tipo Wiley, com malha de $1 \mathrm{~mm}$. Depois de moídas, as alíquotas de 10 gramas de fezes foram enviadas ao Laboratório de Pesquisas em Saúde e Nutrição Animal e Humana, Simões Saliba Ltda-ME. Elas foram analisadas quanto à concentração do indicador LIPE ${ }^{\circledR}$ por Espectroscopia Infravermelho (SALIBA et al., 2013) e também estimada a produção fecal individual.

As amostras dos alimentos (concentrados e gramíneas), sobras e fezes para análise bromatológica foram desidratadas a $65^{\circ} \mathrm{C}$ por 72 horas em estufa de ventilação forçada.

Em seguida, foram moídas em moinho tipo Willey (moinho de facas), com peneira de $1 \mathrm{~mm}$, e armazenadas em frascos plásticos identificados para posterior análise.

As amostras dos concentrados experimentais, aparas da casca de raiz de mandioca, gramínea coletada por pastejo simulado, sobras e fezes foram avaliadas quanto aos teores de matéria seca (MS), proteína bruta ( $\mathrm{PB}$ - metodologia Kjeldahl), extrato etéreo (EE), cinzas (CZ), lignina, carboidratos totais (CHOT) e carboidratos não fibrosos (CNF). A fibra em detergente neutro (FDN), fibra em detergente ácido (FDA), nitrogênio insolúvel em detergente neutro (NIDN) e nitrogênio insolúvel em detergente ácido (NIDA)) foram avaliadas segundo metodologia descritas por Silva e Queiróz (2006) e Detmann et al. (2012).

Como indicador interno, foi utilizada a fibra em detergente neutro indigestível, que foi determinada in situ pelo período de 288 horas.

Para determinação do indicador interno, FDN indigestível, foram utilizadas duas vacas mestiças 
cânuladas no rúmen, que foram alimentadas com feno de Tifton 85 (C. nlemfuensis) ad libitum e $1 \mathrm{~kg}$ de concentrado contendo $36 \%$ de milho moído; 36\% de raiz de mandioca integral moída e desidratada, $14,33 \%$ de farelo de soja, $11,17 \%$ de farelo de algodão, e 2,5\% de ureia. As vacas foram alimentadas com a dieta acima descrita, por dez dias, com o objetivo de adaptar o ambiente ruminal.

Amostras de gramíneas colhidas por pastejo simulado, aparas de casca de raiz de mandioca, sobras e fezes foram acondicionadas em sacos de polipropileno, de TNT com gramatura de $100 \mathrm{~g} \mathrm{~m}^{2}$ ${ }^{-1}$, contendo um grama de amostra por saquinho (20 $\mathrm{mg} \mathrm{cm}{ }^{2-1}$ ) com dimensões de $50 \mathrm{~mm}$ por $100 \mathrm{~mm}$ foram acondicionados em sacos de náilon, presas a uma corrente e incubados por 288 horas no saco ventral do rúmen das vacas canuladas. Em seguida, as amostras foram retiradas e lavadas com água em temperatura ambiente até que a última água de lavagem se apresentasse clara. Após a lavagem, os sacos de polipropileno foram levados à estufa de ventilação forçada, com temperatura de $65^{\circ} \mathrm{C}$ para pré-secagem, durante 72 horas. Após esse processo, foi determinada a fibra em detergente neutro da fração indigestível das amostras, em determinador de fibra Tecnal $\AA$, conforme metodologia descrita por Detmann et al. (2012) e Torres et al. (2009).

$\mathrm{O}$ fracionamento dos compostos nitrogenados foi realizado determinando-se as frações $\mathrm{A}, \mathrm{B}_{1}+\mathrm{B}_{2}$, $\mathrm{B}_{3}$ e C.

A fração A (NNP) foi determinada pela diferença entre o nitrogênio total e o nitrogênio insolúvel em ácido tricloroacético, o qual foi obtido por intermédio do tratamento de aproximadamente $500 \mathrm{mg}$ da amostra com $50 \mathrm{~mL}$ de água destilada, permanecendo por 30 minutos; posteriormente, foram adicionados $10 \mathrm{~mL}$ de ácido tricloroacético (TCA) a 10\%, por 30 minutos (LICITRA; HERNANDEZ; VAN SOEST, 1996). O resíduo remanescente foi filtrado em papelfiltro e, posteriormente, determinado o nitrogênio residual pelo método Kjeldahl, descrito por Silva e Queiróz (2006).
A fração $B_{3}$ foi calculada pela diferença entre o nitrogênio insolúvel em detergente neutro (NIDN) e o nitrogênio insolúvel em detergente ácido (NIDA); e a fração C foi considerada como NIDA, determinada conforme descrito em Silva e Queiróz (2006), e as frações $B_{1}+B_{2}$ foram calculadas pela equação $\mathrm{B}_{1}+\mathrm{B}_{2}=100-\mathrm{A}-\mathrm{B}_{3}-\mathrm{C}$, segundo padronizações de Sniffen et al. (1992) e Licitra, Hernandez e Van Soest (1996).

Os carboidratos das dietas avaliadas foram fracionados em A, $\mathrm{B}_{1}, \mathrm{~B}_{2} \mathrm{e}$ C, conforme proposto por Sniffen et al. (1992), considerando a disponibilidade nutricional e a taxa de degradação ruminal. A fração $\mathrm{A}$, rapidamente degradável no rúmen, é composta principalmente pelos carboidratos solúveis; a fração $\mathrm{B}_{1}$, composta de amido e pectina, possui taxa de degradação superior à taxa de passagem; a fração $\mathrm{B}_{2}$, composta pelos carboidratos fibrosos da parede celular, é de disponibilidade ruminal lenta, portanto, susceptível aos efeitos da taxa de passagem; e a fração $\mathrm{C}$ representa a parede celular indisponível, incluindo a lignina.

As equações para as determinações analíticas dessas frações foram:

1: $\mathrm{A}(\% \mathrm{CT})=[100-\% \mathrm{CNF}] *\left[100-\mathrm{B}_{2}-\right.$ $\mathrm{C}] / 100$

$$
\begin{aligned}
& 2: \mathrm{B}_{1}(\% \mathrm{CT})=\% \mathrm{CNF}^{*}\left[100-\mathrm{B}_{2}-\mathrm{C}\right] / 100 \\
& 3: \mathrm{B}_{2}(\% \mathrm{CT})=100 *\left[\mathrm{FDN}_{\mathrm{cp}}(\% \mathrm{MS})-\mathrm{PIDN}\right. \\
&(\% \mathrm{~PB}) * 0,01 * \mathrm{~PB} \quad(\% \mathrm{MS})-\mathrm{FDN}_{\mathrm{cp}} \\
&(\% \mathrm{MS}) * 0,01 * \text { Lignina }) * 2,4] / \mathrm{CT}(\% \mathrm{MS})
\end{aligned}
$$

$$
\text { 4: } \mathrm{C}(\% \mathrm{CT})=100 *\left[\mathrm{FDN}_{\mathrm{cp}}(\% \mathrm{MS}) * 0,01 *\right.
$$
Lignina* 2,4] / CT(\%MS)

A estimativa da PDR - proteína degradável no rúmen e PNDR - proteína não degradável no rúmen foram calculadas usando o fracionamento dos compostos nitrogenados dos concentrados experimentais, aparas de casca de raiz de mandioca e pastagem, em conjunto com a taxa de degradabilidade estimada (kd) de 0,070 (MARCONDES et al., 2009) e taxa de passagem estimada (kp) de $0,051 \mathrm{~h}^{-1}$, para volumoso, e $0,068 \mathrm{~h}^{-1}$, para concentrado, através das 
fórmulas propostas pelo NRC (2001):

$$
\begin{aligned}
& \mathrm{PDR}=\mathrm{A}+\left(\mathrm{B}_{1}+\mathrm{B}_{2}\right) *\left[\mathrm{kd}\left(\mathrm{B}_{1}+\mathrm{B}_{2}\right) /(\mathrm{kd}+\mathrm{kp})\right] \\
& +\mathrm{B}_{3}^{*}\left[\mathrm{kd} \mathrm{B}_{3} /(\mathrm{kd}+\mathrm{kp})\right] \\
& \mathrm{PNDR}=\left(\mathrm{B}_{1}+\mathrm{B}_{2}\right) *\left[\mathrm{kp}\left(\mathrm{B}_{1}+\mathrm{B}_{2}\right) /(\mathrm{kd}+\mathrm{kp})\right]+ \\
& \mathrm{B}_{3}^{*}\left[\mathrm{kp} \mathrm{B} \mathrm{B}_{3} /(\mathrm{kd}+\mathrm{kp})\right]
\end{aligned}
$$

A estimativa da taxa de passagem $(\mathrm{kp})$ foi calculada utilizando as fórmulas para concentrado e volumosos úmidos, proposta pelo NRC (2001):

Kp concentrado $=3,054+0,614 *(\%$ de ingestão de matéria seca/peso corporal $(3,37 \%))$.

Kp volumosos úmidos $=2,904+1,375^{*}(\%$ de ingestão de matéria seca/peso corporal $(3,37 \%))$ $0,020 *$ (\% de ingestão do concentrado na matéria seca total $(35,91 \%))$.

A estimativa do consumo voluntário de matéria seca foi realizada a partir da FDNi com base na quantificação da indigestibilidade in situ, por 288 horas, sendo o consumo de matéria seca dado pela equação: CMS $\left(\mathrm{kg} \mathrm{dia}^{-1}\right)=\{[(\mathrm{EF}$ x CIF $)$ - IS $] / C I F O\}$ + CMSS; em que: EF = excreção fecal $\left(\mathrm{kg} \mathrm{dia}^{-1}\right)$; $\mathrm{CIF}=$ concentração do indicador nas fezes (\%); IS $=$ indicador presente no suplemento $(\mathrm{kg} / \mathrm{dia}) ; \mathrm{CIFO}$ = concentração do indicador na forragem (\%) e CMSS = consumo de matéria seca do suplemento $\left(\mathrm{kg} \mathrm{dia}^{-1}\right)$ (DETMANN et al., 2001).

A estimativa do consumo voluntário de pastagem (utilizando um quadrado latino, cinco vacas) foi feita subtraindo-se o consumo voluntário de matéria seca total do consumo de matéria seca do concentrado no cocho, conforme a equação: $\operatorname{CMSF}\left(\mathrm{kg} \mathrm{dia}^{-1}\right)=$ CMS (kg dia $\left.{ }^{-1}\right)$ - CMSC (kg dia $\left.{ }^{-1}\right)$; em que: CMSF = consumo de matéria seca de forragem; CMSC $(\mathrm{kg}$ $\left(\operatorname{dia}^{-1}\right)=$ consumo de matéria seca de concentrado.

O cálculo da digestibilidade aparente (D.A) foi realizada utilizando o indicador interno FDNi (fibra em detergente neutro indigestível), através da fórmula:

D.A=100- (100* (\%FDNi na dieta/\%FDNi nas fezes $) *(\%$ do nutriente nas fezes $/ \%$ do nutriente na dieta)) (ANDRIGUETO et al., 1999).
A estimativa de nutrientes digestíveis totais (NDT) dos concentrados experimentais, das aparas de casca de mandioca e da forragem (Tabela 2), e estimativa do consumo de NDT foram efetuadas segundo as equações propostas pelo NRC (2001) e Detmann et al. (2006):

$$
\begin{aligned}
& \text { 5: } \mathrm{NDT}(\%)=\mathrm{CNF}_{\mathrm{d}}+\mathrm{PB}_{\mathrm{d}}+\left(\mathrm{EE}_{\mathrm{d}} * 2,25\right)+ \\
& \quad \mathrm{FDN}_{\mathrm{d}}-7 ; \\
& \text { 6: } \mathrm{CNF}_{\mathrm{d}}=0,98 * \mathrm{CNF} ; \\
& \text { 7: } \mathrm{PB}_{\mathrm{d} \text { (forragem) }}=\mathrm{PB} * e^{-1,2 *(\mathrm{PIDA} / \mathrm{PB})} \text { ou } \mathrm{PB}_{\mathrm{d} \text { (concentrado) }} \\
& \quad=[1-0,4 *(\mathrm{PIDA} / \mathrm{PB})]^{*} \mathrm{~PB} ; \\
& \text { 8: } \mathrm{EE}_{\mathrm{d}}=0,8596 * \mathrm{EE}-0,18 \text { (Detmann et al., } \\
& \text { 2006); } \\
& \text { 9: } \mathrm{FDN}_{\mathrm{d}}=0,75 *[(\mathrm{FDN}-\mathrm{PDIN})-\text { Lignina }] *[ \\
& \\
& \text { 1- } \left.(\text { Lignina/FDN-PIDN })^{0,667}\right]
\end{aligned}
$$
9: $\mathrm{FDN}_{\mathrm{d}}=0,75 *[(\mathrm{FDN}-\mathrm{PDIN})-$ Lignina $] *[$ 1- (Lignina/FDN-PIDN) ${ }^{0,667}$ ]

Para o balanço de energia, foi utilizado um quadrado latino, cinco animais. A quantificação da energia líquida ingerida da dieta total foi obtida segundo a fórmula proposta pelo NRC (2001):

10: $\operatorname{EL}\left(\mathrm{Mcal} \mathrm{kg}^{-1}\right)=(0,0245 * \mathrm{NDT})-0,12$

Foram estimadas as exigências de energia líquida para mantença e produção dos animais, expressas em Mcal dia-1 ${ }^{-1}$, segundo o NRC (2001):

$$
\begin{aligned}
& \text { 11: } \mathrm{EL}_{\text {Mantença }}=0,08 * \mathrm{PV}^{0,75} \\
& \text { 12: } \mathrm{EL}_{\text {Producão }}=\mathrm{PL} *\{0,360+ \\
& [0,0969 *(\% \text { Gordura })]\}
\end{aligned}
$$

13: $\mathrm{EL}_{\text {Gestação }}=[(0,00318 *$ Dias de gestação $0,0352) *$ (Peso do bezerro ao nascer $(\mathrm{kg}) /$ 45)] $/ 0,218$

As abreviações são definidas como: CNF: carboidrato não fibroso; CNFd: carboidrato não fibroso digestível; PB: proteína bruta; PBd: proteína bruta digestível; EE: extrato etéreo; EEd: extrato etéreo digestível; FDN: fibra em detergente neutro; FDNd: fibra em detergente neutro digestível; PDIN: proteína indigestível em detergente neutro; PIDA: proteína indigestível em detergente ácido; $\mathrm{EL}_{\text {mantença: }}$ : energia líquida de mantença; $\mathrm{EL}$ produçãa: energia líquida de produção; PL: produção leiteira; 
$\mathrm{EL}_{\text {Gestacão }}$ : energia líquida de gestação.

Os dados foram submetidos à análise estatística por meio do procedimento PROC GLM, as médias foram obtidas pelo procedimento LSMEANS e foi realizada a comparação entre médias utilizando o desdobramento dos graus de liberdade por meio de contrastes ortogonais, utilizando o programa estatístico SAS (Statistical Analysis System, 2003), versão 9.1 .

\section{Resultados e Discussão}

A ingestão média de matéria seca da dieta total no experimento foi de 20,61 $\pm 1,9 \mathrm{~kg}$, (Tabela 3) semelhante à predição calculada, segundo o NRC (2001) de 19,48 kg.

Não foi constatado efeito da influência dos níveis de substituição do milho moído por raiz de mandioca integral triturada e desidratada no concentrado $(\mathrm{P}>0,05)$ sobre a ingestão de matéria seca (MS) e matéria orgânica (MO).

Não houve efeito da substituição do milho por mandioca integral triturada $(\mathrm{P}>0,05)$ sobre a ingestão de matéria seca da dieta total, expressa em quilogramas; em percentual do peso corporal (IMS $\left.\mathrm{PC}^{-1}\right)$ ou em gramas por unidade do peso metabólico (g peso metabólico ${ }^{-1}$ ). As médias encontradas neste trabalho $\left(167,18 \mathrm{~g}\right.$ de MS kg peso metabólico $\left.{ }^{-1}\right)$ foram superiores às relatadas por Lima et al. (2008), que avaliaram a inclusão de diferentes níveis de bagaço de mandioca na silagem de capim elefante, e encontraram ingestão de $134,51 \mathrm{~g}$ de MS kg peso metabólico ${ }^{-1} \mathrm{em}$ vacas lactantes. Também foi inferior à média descrita por Dias et al. (2008) (114,13 g MS kg peso metabólico ${ }^{-1}$ ), avaliando bagaço de mandioca em substituição ao milho no concentrado para novilhas leiteiras em crescimento, provavelmente, devido à menor exigência nutricional desta última categoria. Já, os valores encontrados neste estudo foram semelhantes aos de Vilela et al. (2006) que encontraram média de 182,61 $\mathrm{g}$ de $\mathrm{MS} \mathrm{kg}{ }^{-1}$ de peso metabólico, em vacas da raça Holandesa com peso corporal médio de $550 \mathrm{~kg}$, consumindo dietas constituídas por pastagem irrigada de gramínea Cynodon dactylon cv. Coastcross, e suplementada com $6 \mathrm{~kg}$ de concentrado. Pastagens tropicais irrigadas e adubadas, manejadas com lotações rotativas e suplementadas com concentrados, resultam em ingestões de matéria seca superiores e, provavelmente por isso, os resultados descritos neste ensaio apresentaram-se também maiores.

Não foram observados diferenças significativas entre os níveis de substituição de milho moído por raiz de mandioca integral moída e desidratada no concentrado $(\mathrm{P}>0,05)$ para a ingestão de proteína bruta (PB), extrato etéreo (EE), fibra em detergente neutro corrigida para cinzas e proteína (FDNcp), carboidratos totais (CHOT), carboidratos não fibrosos (CNF) e nutrientes digestíveis totais (NDT), conforme descritos na Tabela 3.

Não houve diferença significativa dos níveis de substituição do milho moído pela raiz de mandioca integral moída e desidratada no concentrado $(\mathrm{P}>0,05)$ na ingestão de matéria seca em razão ao peso metabólico $\left(\mathrm{PM}^{-1}\right)$; no percentual de ingestão de matéria seca e matéria orgânica de concentrado e pastagem em razão ao peso corporal $\left(\mathrm{PC}^{-1}\right)$ e na proporção de ingestão de volumoso e concentrado (Tabela 3). 
Tabela 3. Consumos médios diários de matérias seca, orgânica e nutrientes; ingestão de matéria seca em razão ao peso metabólico, percentuais de ingestão de matérias seca e orgânica em razão do peso corporal, produção leiteira.

\begin{tabular}{|c|c|c|c|c|c|c|c|c|c|c|}
\hline \multirow[t]{2}{*}{ itens } & \multicolumn{5}{|c|}{$\begin{array}{l}\text { Níveis de Substituição do milho por raiz de } \\
\text { mandioca }(\%)\end{array}$} & \multirow[t]{2}{*}{ C.V. } & \multicolumn{3}{|c|}{ Efeito } & \multirow[t]{2}{*}{ EQ. } \\
\hline & 0 & 25 & 50 & 75 & 100 & & $\mathrm{~L}$ & Q & F.A. & \\
\hline \multicolumn{11}{|l|}{ Dieta total } \\
\hline $\mathrm{MS}^{1}$ & 19,81 & 20,83 & 20,71 & 20,87 & 20,81 & 9,21 & 0,4602 & 0,5661 & 0,8404 & $\hat{\mathrm{Y}}=20,61$ \\
\hline$\%$ IMS PC ${ }^{-1}$ & 3,22 & 3,31 & 3,40 & 3,49 & 3,41 & 9,08 & 0,2228 & 0,5004 & 0,8509 & $\hat{\mathrm{Y}}=3,37$ \\
\hline $\mathrm{IMS} \mathrm{PM}^{-12}$ & 159,96 & 165,69 & 168,69 & 172,35 & 169,22 & 8,74 & 0,2464 & 0,4983 & 0,9255 & $\hat{\mathrm{Y}}=167,18$ \\
\hline $\mathrm{MO}^{1}$ & 17,76 & 18,69 & 18,53 & 18,74 & 18,62 & 9,10 & 0,4686 & 0,5465 & 0,8073 & $\hat{\mathrm{Y}}=18,47$ \\
\hline $\mathrm{PB}^{1}$ & 3,18 & 3,30 & 3,24 & 3,37 & 3,26 & 9,88 & 0,6436 & 0,6329 & 0,6126 & $\hat{\mathrm{Y}}=3,27$ \\
\hline $\mathrm{EE}^{1}$ & 0,79 & 0,76 & 0,76 & 0,79 & 0,79 & 21,05 & 0,8840 & 0,7755 & 0,9427 & $\hat{\mathrm{Y}}=0,78$ \\
\hline $\mathrm{FDN}_{\mathrm{cp}}{ }^{1}$ & 7,89 & 7,98 & 8,14 & 7,92 & 7,87 & 12,19 & 0,9462 & 0,7065 & 0,9277 & $\hat{\mathrm{Y}}=7,96$ \\
\hline CHOT $^{1}$ & 13,74 & 14,51 & 14,84 & 14,58 & 14,74 & 11,06 & 0,3801 & 0,5135 & 0,8191 & $\hat{\mathrm{Y}}=14,48$ \\
\hline $\mathrm{CNF}^{1}$ & 5,80 & 5,75 & 6,46 & 6,71 & 6,19 & 12,36 & 0,5495 & 0,1110 & 0,3231 & $\hat{\mathrm{Y}}=6,18$ \\
\hline $\mathrm{NDT}^{1}$ & 11,32 & 11,87 & 11,78 & 12,22 & 11,95 & 10,96 & 0,3983 & 0,6200 & 0,7851 & $\hat{\mathrm{Y}}=11,83$ \\
\hline \multicolumn{11}{|c|}{ Proporção Volumoso : Concentrado } \\
\hline $\begin{array}{l}\text { \% de Ing. de } \\
\text { Pastagem }\end{array}$ & 65,73 & 61,76 & 66,31 & 61,61 & 65,06 & 6,99 & 0,8192 & 0,4703 & - & $\hat{\mathrm{Y}}=64,09$ \\
\hline $\begin{array}{l}\% \text { de Ing. de } \\
\text { Concent. }\end{array}$ & 34,27 & 38,24 & 33,69 & 38,39 & 34,94 & 12,48 & 0,8192 & 0,4703 & - & $\hat{\mathrm{Y}}=35,91$ \\
\hline \multicolumn{11}{|l|}{ Pastagem } \\
\hline $\mathrm{MS}^{1}$ & 13,10 & 12,91 & 13,71 & 12,87 & 13,50 & 14,58 & 0,7836 & 0,9989 & 0,5294 & $\hat{\mathrm{Y}}=13,22$ \\
\hline$\%$ IMS PC ${ }^{-1}$ & 2,11 & 2,03 & 2,27 & 2,16 & 2,24 & 13,73 & 0,3714 & 0,9371 & 0,3074 & $\hat{Y}=2,16$ \\
\hline $\mathrm{MO}^{1}$ & 11,62 & 11,45 & 12,16 & 11,42 & 11,97 & 14,57 & 0,7851 & 0,9979 & 0,5305 & $\hat{\mathrm{Y}}=11,72$ \\
\hline$\%$ IMO PC $^{-1}$ & 1,87 & 1,80 & 2,02 & 1,92 & 1,99 & 13,73 & 0,3760 & 0,9360 & 0,3089 & $\hat{\mathrm{Y}}=1,92$ \\
\hline \multicolumn{11}{|l|}{ Concentrado } \\
\hline $\mathrm{MS}^{1}$ & 6,71 & 7,92 & 7,00 & 8,00 & 7,31 & 9,59 & 0,2294 & 0,1389 & - & $\hat{\mathrm{Y}}=7,39$ \\
\hline$\%$ IMS PC $^{-1}$ & 1,10 & 1,28 & 1,13 & 1,32 & 1,17 & 12,97 & 0,4681 & 0,2500 & - & $\hat{\mathrm{Y}}=1,20$ \\
\hline \multicolumn{11}{|l|}{ Desempenho } \\
\hline $\begin{array}{l}\text { Produção Leite } \\
\left(\mathrm{kg} \mathrm{dia}^{-1}\right)\end{array}$ & 19,60 & 21,60 & 20,53 & 21,62 & 20,85 & 7,58 & 0,2047 & 0,2253 & 0,1032 & $\hat{\mathrm{Y}}=20,84$ \\
\hline $\begin{array}{l}\mathrm{kg}^{2}{ }^{2} \mathrm{~g} \mathrm{~kg}^{-1} ;{ }^{3} \text { Corl } \\
\text { rporal; IMS PM PM } \\
\text { éreo; FDNcp - fib } \\
\text { prosos; NDT - nut }\end{array}$ & para & IE & 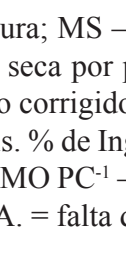 & ateria & $\%$ IV & $-\mathrm{pel}$ & 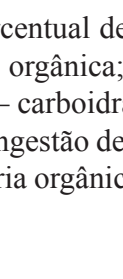 & ngesta & matern & $\begin{array}{l}\text { seca por } p \\
\mathrm{EE}-\text { extr }\end{array}$ \\
\hline
\end{tabular}

Fonte: Elaboração dos autores.

Segundo Berchielli, Pires e Oliveira (2011), o consumo mínimo de pasto é estimado em aproximadamente $2 \mathrm{~kg}$ de matéria seca por $100 \mathrm{~kg}$ de peso corporal, podendo ser reduzido este consumo se a forragem apresentar restrições físicas ao consumo e ou baixo valor nutricional. Com base na proporção sugerida pelos pesquisadores, infere-se que, para $616,9 \pm 39 \mathrm{~kg}$ de peso corporal médio das vacas do experimento (Tabela 4), o consumo estimado de matéria seca de pasto seria aproximadamente de $12,32 \mathrm{~kg}$, portanto, semelhante ao valor obtido de ingestão de matéria seca de volumoso, com média 
de $13,22 \pm 1,93 \mathrm{~kg}$.

Observou-se que a substituição de milho moído por raiz de mandioca integral moída e desidratada no concentrado, entre os níveis estudados, não alterou $(\mathrm{P}>0,05)$ a ingestão matéria seca de pastagem.

Maixner et al. (2007), avaliando o consumo de pastagens de Capim elefante anão (Pennisetum purpureum SHUM. cv. Mott) e Tifton 85 (Cynodon nlemfuensis) em vacas da raça Holandesa, com peso médio de $538 \mathrm{~kg}$ e 110 dias de lactação ao início do experimento, obtiveram médias de ingestão de matéria seca de 11,8 e 11,9 kg/vaca/dia, e a razão entre a ingestão de matéria seca de pastagem e o peso corporal dos animais apresentaram médias de 2,21 e 2,20\%, respectivamente, para as gramíneas. Considerando as diferenças dos pesos corporais dos animais utilizados neste experimento $(616,93 \pm 39$ $\mathrm{kg}$, Tabela 4), as médias de ingestão de matéria seca de forragem foram semelhantes à encontrada neste trabalho $(13,22 \mathrm{~kg} / \mathrm{vaca} / \mathrm{dia})$, e também para as médias percentuais de ingestão de matéria seca pelo peso corporal, que neste experimento foi de $3,37 \pm 0,31 \%$.

Não houve diferença significativa $(\mathrm{P}>0,05)$ dos diferentes níveis de substituição de milho moído por raiz de mandioca integral moída e desidratada nos concentrados sobre o desempenho leiteiro.

As reduzidas variações dos pesos corporais e metabólicos dos animais ( $\mathrm{P}>0,05$ (Tabela 4), podem ter ocorrido em função da ausência de variação $(\mathrm{P}>0,05)$ na ingestão de matéria seca total entre os animais dos tratamentos, durante o período experimental (Tabela 3), bem como em função da ausência de efeito dos níveis de substituição do milho moído por raiz de mandioca no balanço de ingestão de energia.

Tabela 4. Médias de pesos corporal e metabólico das vacas que consumiram as dietas experimentais.

\begin{tabular}{|c|c|c|c|c|c|c|c|c|c|}
\hline \multirow{2}{*}{$\begin{array}{c}\text { itens } \\
\text { (peso kg) }\end{array}$} & \multicolumn{5}{|c|}{ Níveis de Substituição do milho por raiz de mandioca (\%) } & \multirow{2}{*}{ C.V. } & \multicolumn{3}{|c|}{ Efeito } \\
\hline & 0 & 25 & 50 & 75 & 100 & & $\mathrm{~L}$ & $\mathrm{Q}$ & FA \\
\hline Corporal & $618,0 \pm 39$ & $632,8 \pm 40$ & $610,8 \pm 39$ & $606,1 \pm 38$ & $616,9 \pm 39$ & 6,34 & 0,6128 & 0,8909 & 0,3820 \\
\hline Metabólico & $123,74 \pm 6$ & $125,05 \pm 6$ & $122,73 \pm 6$ & $122,05 \pm 6$ & $123,69 \pm 6$ & 4,71 & 0,6278 & 0,8967 & 0,3685 \\
\hline
\end{tabular}

$\mathrm{EQ}$.= equação de regressão $\mathrm{L}=$ linear, $\mathrm{Q}=$ quadrático, F.A. = falta de ajuste.

Fonte: Elaboração dos autores.

Verificou-se que a exigência de energia líquida calculada das vacas do experimento, (20,27 Mcal $\mathrm{dia}^{-1}$ ) utilizando vacas com peso corporal médio de $616,9 \pm 39 \mathrm{~kg}$ e produção de leite média de $20,84 \mathrm{~kg}$ e $4,0 \%$ de gordura, e para PB com $14,8 \%$, observouse que os consumos médios encontrados de energia líquida e PB, respectivamente, foram de 30,93\% e $6,9 \%$ mais elevados do que os recomendados pelo NRC (2001), fazendo com que o balanço energético tenha sido positivo.

A exigência mínima de ingestão de FDN em vacas em lactação, segundo o NRC (2001), é de $25 \%$ na matéria seca. O percentual estimado de ingestão de FDNcp da dieta total foi 58,76\% maior do que o mínimo citado pela literatura. A elevada proporção de fibra em detergente neutro, comum em gramíneas tropicais, e a proporção de ingestão da mesma $(64,09 \%$, Tabela 3$)$ foram os fatores que influenciaram nos níveis mais elevados de ingestão de FDN em relação ao descrito no NRC (2001).

O consumo médio de CNF (31,14\%, Tabela 5) ficou abaixo do valor máximo estimado pelo NRC (2001), que preconiza um consumo de até $40 \%$ destes nutrientes. Acredita-se que não houve ocorrência de acidose subclínica ou outros problemas metabólicos, pois, segundo a literatura 
citada, estas ocorrências têm mais chances de carboidratos não fibrosos acima dos percentuais já incidirem sobre os animais, quando estes ingerem citados.

Tabela 5. Ingestão media diária de nutrientes ${ }^{1}$

\begin{tabular}{|c|c|c|c|c|c|c|c|c|c|c|}
\hline \multirow[t]{2}{*}{ itens } & \multicolumn{5}{|c|}{$\begin{array}{l}\text { Níveis de Substituição do milho por raiz de } \\
\text { mandioca (\%) }\end{array}$} & \multirow[t]{2}{*}{ C.V. } & \multicolumn{3}{|c|}{ Efeito } & \multirow[t]{2}{*}{ EQ. } \\
\hline & 0 & 25 & 50 & 75 & 100 & & $\mathrm{~L}$ & $\mathrm{Q}$ & F.A. & \\
\hline$\%$ PB & 16,11 & 15,90 & 15,71 & 16,29 & 15,61 & 3,25 & 0,4244 & 0,4244 & - & $\hat{\mathrm{Y}}=15,92$ \\
\hline$\%$ FDNcp & 39,75 & 38,29 & 39,34 & 38,04 & 38,87 & 5,16 & 0,5251 & 0,5469 & 0,2542 & $\hat{\mathrm{Y}}=38,86$ \\
\hline$\% \mathrm{CNF}$ & 29,93 & 33,96 & 32,79 & 32,60 & 30,86 & 9,42 & 0,9141 & 0,0745 & 0,3113 & $\hat{\mathrm{Y}}=32,03$ \\
\hline$\%$ NDT & 57,05 & 57,13 & 57,07 & 58,78 & 57,21 & 5,00 & 0,6373 & 0,7570 & 0,3883 & $\hat{\mathrm{Y}}=57,45$ \\
\hline
\end{tabular}

Fonte: Elaboração dos autores.

Outro fator que contribuiu para esta inferência foi a administração de bicarbonato de sódio em todos os concentrados no cocho, para prevenção de acidose ruminal, devido ao elevado consumo de concentrado.
Os coeficientes de digestibilidade aparente dos nutrientes não diferiram com a substituição do milho moído por raiz de mandioca integral triturada e seca no concentrado $(\mathrm{P}>0,05)$, (Tabela $6)$.

Tabela 6. Digestibilidade aparente dos nutrientes da dieta total.

\begin{tabular}{|c|c|c|c|c|c|c|c|c|c|c|}
\hline \multirow[t]{2}{*}{ itens } & \multicolumn{5}{|c|}{$\begin{array}{l}\text { Níveis de Substituição do milho por raiz de } \\
\text { mandioca }(\%)\end{array}$} & \multirow[t]{2}{*}{ C.V. } & \multicolumn{3}{|c|}{ Efeito } & \multirow[t]{2}{*}{ EQ. } \\
\hline & 0 & 25 & 50 & 75 & 100 & & $\mathrm{~L}$ & Q & F.A. & \\
\hline MS & 59,72 & 60,21 & 60,38 & 57,97 & 59,74 & 5,23 & 0,6224 & 1,00 & 0,2349 & $\hat{\mathrm{Y}}=59,60$ \\
\hline PB & 60,62 & 59,75 & 61,10 & 59,26 & 60,46 & 6,93 & 0,8930 & 0,8956 & 0,5773 & $\hat{\mathrm{Y}}=60,24$ \\
\hline $\mathrm{EE}$ & 70,11 & 60,76 & 61,65 & 59,63 & 63,19 & 13,36 & 0,2330 & 0,1301 & 0,5528 & $\hat{\mathrm{Y}}=63,07$ \\
\hline FDNcp & 53,50 & 54,48 & 60,91 & 54,41 & 57,55 & 12,96 & 0,5238 & 0,5344 & 0,1337 & $\hat{\mathrm{Y}}=56,17$ \\
\hline CHOT & 60,61 & 61,83 & 62,48 & 61,41 & 62,18 & 7,38 & 0,6796 & 0,7399 & 0,8073 & $\hat{\mathrm{Y}}=61,70$ \\
\hline CNF & 70,26 & 71,92 & 62,36 & 68,59 & 67,16 & 11,60 & 0,4860 & 0,5202 & 0,0953 & $\hat{\mathrm{Y}}=68,06$ \\
\hline
\end{tabular}

Matéria seca (MS), proteína bruta (PB), extrato etéreo (EE), fibra em detergente neutro corrigido para cinzas e proteína (FDNcp), carboidratos totais (CHOT) e carboidratos não fibrosos $(\mathrm{CNF})$; EQ.= equação de regressão $\mathrm{L}=$ linear, $\mathrm{Q}=$ quadrático, $\mathrm{F}$.A. = falta de ajuste.

Fonte: Elaboração dos autores.

Ramalho et al. (2006), substituindo o milho moído no concentrado por raspa de mandioca, nos níveis de $0 ; 25 ; 50 ; 75$ e $100 \%$ e, utilizando como volumosos $29 \%$ de palma forrageira e $26,1 \%$ de silagem de sorgo, também não encontraram diferença nos coeficientes $(\mathrm{P}>0,05)$ de digestibilidade, com médias de 68,04; 72,64; 69,65; 79,37 e 58,04; para MS, PB, CHOT, CNF e FDN, respectivamente, 
exceto para EE, que teve maior digestibilidade no nível de 55,86\% de substituição.

Dentro da fração $\mathrm{B}_{1}$ dos carboidratos, presente em cereais e tubérculos, está o amido, que é composto por amilose e amilopectina. A proporção desse polímero linear (amilose) e do ramificado (amilopectina), presentes nos grãos, influenciam a taxa de degradação e a digestibilidade do amido, ou seja, a digestibilidade do amido é inversamente proporcional ao teor de amilose, visto que quanto maior o teor de amilose, menor é a digestibilidade. Outro fator que pode reduzir a digestibilidade do amido é a interação com a matriz proteica, que tem pouca permeabilidade à água e à atividade enzimática microbiana. Dessa forma, fontes de amido com maiores teores de amilopectina, como o grão de milho imaturo, podem apresentar maior digestibilidade (JOBIM; BRANCO; SANTOS, 2003; GONÇALVES; BORGES, I.; FERREIRA, 2009).

A inexistência de diferença entre os coeficientes de digestibilidade das dietas contendo milho moído ou raiz de mandioca integral moída e desidratada no concentrado evidencia a existência de um equilíbrio no fornecimento dos nutrientes presentes nas dietas isonitrogenadas e isoenergéticas avaliadas. A hipótese da existência de diferenças nos valores de digestibilidade entre os ingredientes energéticos utilizados (milho e mandioca) nos concentrados experimentais testados não foi confirmada neste experimento. Os concentrados com maior teor de raiz de mandioca moída, potencialmente de melhor utilização pela microbiota ruminal, devido à ausência de proteínas estruturais, como as prolaminas, envolvendo os grânulos de amido, não apresentaram digestibilidade superior a do milho. A granulometria do milho, finamente moído nos concentrados, provavelmente, atuou como um facilitador da atividade enzimática da microbiota ruminal, contribuindo para maior degradabilidade ruminal e intestinal, aumentando a superfície de contato do alimento para a colonização microbiana.

Pina et al. (2006), encontraram valores de digestibilidade da matéria seca e proteína bruta do farelo de algodão de 68,19 e 72,57\%, respectivamente, e do farelo de soja, de 59,85 e $68,39 \%$, respectivamente. Portanto, supõe-se que as dietas contendo mais milho poderiam ter sua digestibilidade diminuída pela maior participação do farelo de algodão, mas isto não foi verificado no experimento.

Segundo Simas et al. (2008), o amido de milho grosseiramente moído apresenta menor digestibilidade no trato digestivo total, comparada ao milho finamente moído e milho floculado.

Os valores dos coeficientes de digestibilidade encontrados neste trabalho, provavelmente estão relacionados ao teor de concentrado na dieta.

Não foram observadas diferenças significativas $(\mathrm{P}>0,05)$ na ingestão de energia líquida nos diferentes níveis de substituição do milho moído por raiz de mandioca integralmente moída e desidratada nos concentrados experimentais (Tabela 7).

O balanço de energia líquida apresentou-se positivo e as exigências de energia líquida foram supridas, excedendo à demanda energética de 20,27 Mcal dia ${ }^{-1}$. 
Tabela 7. Balanço de energia líquida.

\begin{tabular}{|c|c|c|c|c|c|c|c|c|c|c|}
\hline \multirow[t]{2}{*}{ Itens } & \multicolumn{5}{|c|}{$\begin{array}{l}\text { Níveis de Substituição do milho por raiz de } \\
\text { mandioca }(\%)\end{array}$} & \multirow[t]{2}{*}{$\mathrm{CV}$} & \multicolumn{3}{|c|}{ Efeito } & \multirow[t]{2}{*}{ EQ. } \\
\hline & 0 & 25 & 50 & 75 & 100 & & $\mathrm{~L}$ & Q & FA & \\
\hline EL (ingerida) ${ }^{1}$ & 25,56 & 26,59 & 26,84 & 27,43 & 27,01 & 11,44 & 0,4028 & 0,6253 & 0,9522 & $\hat{\mathrm{Y}}=26,69$ \\
\hline EL (mantença) $)^{1}$ & 9,90 & 10,08 & 9,82 & 9,76 & 9,90 & 4,71 & 0,6278 & 0,8967 & 0,3685 & $\hat{\mathrm{Y}}=9,89$ \\
\hline EL (produção) ${ }^{1}$ & 7,43 & 9,13 & 7,93 & 9,10 & 8,32 & 20,13 & 0,4773 & 0,3766 & 0,1266 & $\hat{Y}=8,38$ \\
\hline EL (gestação) ${ }^{1}$ & 1,68 & 2,46 & 2,30 & 1,56 & 2,25 & 43,97 & 0,8580 & 0,6521 & 0,0572 & $\hat{Y}=2,05$ \\
\hline $\mathrm{BEL}^{1}$ & 6,55 & 4,92 & 6,79 & 7,00 & 6,55 & 60,35 & 0,7069 & 0,9163 & 0,4834 & $\hat{\mathrm{Y}}=6,36$ \\
\hline
\end{tabular}

${ }^{1}$ Mcal dia $^{-1}$; EL (ingerida): Exigência de energia líquida de mantença; EL (produção): Exigência de energia líquida para produção; EL (gestação): Exigência de energia líquida para gestação; BEL: Balanço de energia líquida; EQ.= equação de regressão L = linear, $\mathrm{Q}=$ quadrático, $\mathrm{FA}=$ falta de ajuste.

Fonte: Elaboração dos autores.

Ramalho et al. (2006), avaliando o balanço de energia líquida encontraram médias de 2,48; 2,13; 2,97; 3,72; e 3,66 Mcal dia $^{-1}$ em vacas lactantes consumindo dietas contendo concentrados com substituição do milho moído por raspa de mandioca, nos níveis de $0 ; 25 ; 50 ; 75$ e $100 \%$ e, utilizando como volumosos $29 \%$ de palma forrageira e $26,1 \%$ de silagem de sorgo, suprindo as necessidades de produção leiteira. Os concentrados avaliados no presente experimento supriram as exigências de energia líquida apresentando balanço energético positivo.

O balanço de energia apresenta importância significativa na avaliação do potencial que a raiz de mandioca integral triturada e desidratada no concentrado apresenta para o suprimento das demandas de energia de vacas lactantes para manutenção corporal, desenvolvimento da gestação e produtividade leiteira.

Os resultados do balanço de energia mostram que a raiz integral de mandioca triturada e desidratada, se comparado ao milho moído como fonte de carboidrato, apresenta-se como um ingrediente adequado no balanceamento de concentrados.

\section{Conclusão}

Pode-se concluir que a raiz de mandioca integralmente moída e desidratada pode substituir até $72 \%$ do milho em dietas concentradas para vacas lactantes em pastejo.

\section{Agradecimentos}

Ao Programa de Pós Graduação em Zootecnia e Universidade Estadual do Sudoeste da Bahia por todo apoio durante todo o processo de desenvolvimento do curso de mestrado, à CAPES pela concessão da bolsa, ao senhor Jorge Ferreira Almeida e esposa, proprietários do Sítio Beija Flor, e aos professores Dr. Sc. Mauro Pereira de Figueiredo (Orientador), Dr. Sc. Paulo Bonomo (Co-orientador) e Dra ${ }^{a}$ Sc. Mara Lúcia Albuquerque Pereira (Colaboradora) por todo auxílio no desenvolvimento deste trabalho.

\section{Referências}

ANDRIGUETO, J. M.; PERLY, L.; MINARDI, I.; GEMAEL, A.; FLEMMING, J. S.; SOUZA, G. A.; BONA FILHO, A. Nutrição Animal. 6. ed. São Paulo: Nobel, 1999. v. 1, 395 p.

BERCHIELLI, T. T.; PIRES, A. V.; OLIVEIRA, S. G. Nutrição de ruminantes. 2. ed. Jaboticabal: Funep, 2011. $616 \mathrm{p}$.

DERESZ, F. Produção de leite de vacas mestiças Holandês x Zebu em pastagem de capim-elefante, manejada em sistema rotativo com e sem suplementação durante a época das chuvas. Revista Brasileira de Zootecnia, Viçosa, MG, v. 30, n. 1, p. 197-204, 2001. 
DETMANN, E.; PAULINO, M. F.; ZERVOUDAKIS, J. T.; VALADARES FILHO, S. C.; EUCLYDES, R. F.; LANA, R. P.; QUEIROZ, D. S. Cromo e indicadores internos na determinação do consumo de novilhos mestiços, suplementados, a pasto. Revista Brasileira de Zootecnia, Viçosa, MG, v. 30, n. 5, p. 1600-1609, 2001.

DETMANN, E.; SOUZA, M. A.; VALADARES FILHO, S. C.; QUEIROZ, A. C.; BERCHIELLI, T. T.; SALIBA, E. O. S.; CABRAL, L. S.; PINA, D. S.; LADEIRA, M. M.; AZEVEDO, J. A. G. Métodos para análise de alimentos - INCT - ciência animal. Visconde do Rio Branco: Suprema, 2012. 214 p.

DETMANN, E.; VALADARES FILHO, S. C.; PINA, D. S.; CAMPOS, J. M. S.; PAULINO, M. F.; OLIVEIRA, A. S.; SILVA, P. A. Estimação da digestibilidade do extrato etéreo em ruminantes a partir dos teores dietéticos: desenvolvimento de um modelo para condições brasileiras. Revista Brasileira de Zootecnia, Viçosa, MG, v. 35, n. 4, p.1469-1478, 2006.

DIAS, A. M.; SILVA, F. F.; VELOSO, C. M.; ÍTAVO, L. C. V.; PIRES, A. J. V.; SOUZA, D. R.; SÁ, J. F.; MENDES, F. B. L.; NUNES NASCIMENTO, P. V. Bagaço de mandioca em dietas de novilhas leiteiras: consumo de nutrientes e desempenho produtivo. Arquivo Brasileiro de Medicina Veterinária e Zootecnia, Belo Horizonte, v. 60, n. 4, p. 987-995, 2008.

GONÇALVES, L. C.; BORGES, I.; FERREIRA, P. D. S. Alimentos para gado de leite. Belo Horizonte: Editora FEPMVZ, 2009. 568 p.

JOBIM, C. C.; BRANCO, A. B.; SANTOS, G. T. Silagem de grãos úmidos na alimentação de bovinos leiteiros. In: SIMPÓSIO GOIANO SOBRE MANEJO E NUTRIÇÃO DE BOVINOS DE CORTE E LEITE, 5., 2003. Anais... Goiânia: UEM, 2003. p. 357-376.

LICITRA, G.; HERNANDEZ, T. M.; VAN SOEST, P. J. Standardization of procedures for nitrogen fractionation of ruminant feeds. Animal Feed Science and Technology, Amsterdam, v. 57, n. 4, p. 347-358, 1996.

LIMA, L. P.; VELOSO, C. M.; SILVA, F. F.; BONOMO, P.; PINHEIRO, A. A.; DUTRA, G. S.; PEREIRA JUNIOR, I. G.; VELOSO, J. M. C. Bagaço de mandioca (Manihotesculenta, Cranz) na dieta de vacas leiteiras e consumo de nutrientes. Arquivo Brasileiro de Medicina Veterinária e Zootecnia, Belo Horizonte, v. 60, n. 4, p. 1004-1010, 2008.

MAIXNER, A. R.; QUADROS, F. L. F.; KOZLOSKI, D. P. M.; ROSSI, G. E.; AURÉLIO, N. D. Consumo de forragem e desempenho de vacas holandesas sob pastejo de gramíneas tropicais. Acta Scientiarum. Animal Science, Maringá, v. 29, n. 3, p. 241-248, 2007.
MARCONDES, M. I.; VALADARES FILHO, S. C.; DETMANN, E.; VALADARES, R. F. D.; COSTA E SILVA, L. F.; FONSECA, M. A. Degradação ruminal e digestibilidade intestinal da proteína bruta de alimentos para bovinos. Revista Brasileira de Zootecnia, Viçosa, v. 38, n. 11, p. 2247-2257, 2009.

NACIONAL RESEARCH COUNCIL - NRC. Nutrient requirements of dairy cattle. $7^{\text {th }}$ ed. Washington, D.C. USA: National Academy Press, 2001. 406 p.

PINA, D. S.; VALADARES FILHO, S.C.; VALADARES, R. F. D.; CAMPOS, J. M. S.; DETMANN, E.; MARCONDES, M. I.; OLIVEIRA, A. S.; TEIXEIRA, R. M. A. Consumo e digestibilidade aparente total dos nutrientes, produção e composição do leite de vacas alimentadas com dietas contendo diferentes fontes de proteína. Revista Brasileira de Zootecnia, Viçosa, MG, v. 35, n. 4, p. 1543-1551, 2006.

RAMALHO, R. P.; FERREIRA, M. A.; VÉRAS, A. S. C.; LIMA, L. E.; ROCHA, V. R. R. A. Substituição do milho pela raspa de mandioca em dietas para vacas primíparas em lactação. Revista Brasileira de Zootecnia, Viçosa, MG, v. 35, n. 3, p. 1221-1227, 2006. Suplemento.

RANGEL, A. H. N.; LEONEL, F. P.; BRAGA, A. P.; PINHEIRO, M. J. P.; LIMA JÚNIOR, D. M. Utilização da mandioca na alimentação de ruminantes. Revista Verde, Mossoró, v. 3, n. 2, p. 1-12, abr./jun. 2008.

SALIBA, E. O. S.; GONÇALVES, N. C.; BARBOSA, G. S. S. C.; MOREIRA, G. R.; FREITAS, R. M.; SILVA, F. A. Evaluation of the infrared spectroscopy method for the quantification of NANOLIPE marker in feces of dairy cattle. In: EAAP INTERNATIONAL SYMPOSIUM ON ENERGY AND PROTEIN METABOLISM AND NUTRITION, 4., 2013. Califórnia. Proceedings... Califórnia: Springer, 2013. p. 247-248.

SILVA, D. J.; QUEIROZ, A. C. de. Análise de alimentos: métodos químicos e biológicos. 3. ed. Viçosa: UFV, 2006. $235 \mathrm{p}$.

SIMAS, J. M. C.; PIRES, A. V.; SUSIN, I.; SANTOS, F. A. P.; MENDES, C. Q.; OLIVEIRA, R. C.; FERNANDES, J. J. R. Efeitos de fontes e formas de processamento do amido na utilização de nutrientes e parâmetros ruminais de vacas em lactação. Arquivo Brasileiro de Medicina Veterinária e Zootecnia, Belo Horizonte, v. 60, n. 5, p. 1128-1134, 2008.

SNIFFEN, C. J.; O'CONNOR, J. D.; VAN SOEST, P. J.; FOX, D. G.; RUSSELL, J. B. A net carbohydrate and protein system for evaluating cattle diets: II. Carbohydrate and protein availability. Journal of Animal Science, Champaign, v. 70, n. 7, p. 3562-3577, 1992. 
TORRES, L. C.; FERREIRA, M. A.; GUIM, A.; VILELA, D.; LIMA, J. A.; RESENDE, J. C.; VILELA, M. S.; GUIMARÃES, A. V.; SILVA, E. C. VERNEQUE, R. S. Desempenho de vacas da raça Substituição da palma-gigante por palma-miúda em Holandesa em pastagem de coastcross. Revista dietas para bovinos em crescimento e avaliação de Brasileira de Zootecnia, Viçosa, MG, v. 35, n. 2, p. 555indicadores internos. Revista Brasileira de Zootecnia, 561, 2006.

Viçosa, MG, v. 38, n. 11, p. 2264-2269, 2009. 
